\title{
Penile nodules revealing systemic amyloidosis associated with myeloma
}

\author{
Loubab Omahsan', Nassiba Zerrouki', Nada Zizi ${ }^{1,2}$, Siham Dikhaye ${ }^{1,2}$ \\ ${ }^{1}$ Department of Dermatology, Mohammed 6 University Hospital of Oujda - University of Mohammed First - Faculty of \\ Medicine and Pharmacy, Oujda, Morocco, ${ }^{2}$ Laboratory of Epidemiology, Public Health and Scientific Research, Oujda, \\ Morocco
}

Corresponding author: Dr. Loubab Omahsan, E-mail: oloubab@gmail.com

\begin{abstract}
Amyloidosis is a rare disease. Nodular cutaneous amyloidosis is the rarest clinical form of cutaneous amyloidosis. It may be associated with a systemic disease. We report an exceptional case of amyloidosis associated with myeloma, with a double atypical localization: Well-defined papulo-nodules of the base of the penis; Vertebral amyloidosis causing spinal cord compression. The association of nodular skin lesions to a myeloma should evoke the diagnosis of amyloidosis.
\end{abstract}

Key words: Penile nodules; Amyloidosis; Spinal cord compression; Myeloma

\section{INTRODUCTION}

Amyloidosis is a rare disorder characterized by the deposition of insoluble proteins in tissues. Nodular cutaneous amyloidosis (ACN) is the rarest form of cutaneous amyloidosis. Only a dozen cases of skin amylosis of the glans of the penis have been reported until today [1]. We describe the case of systemic amyloidosis with atypical presentation.

\section{CASE REPORT}

A 57-year-old patient with no significant pathological history has been followed for two months for multiple myeloma retained on the presence of medullary plasmocytosis, monoclonal gammopathy type Lambda and two CRAB criteria (Hypercalcemia, renal failure, anemia $<\mathrm{l} 0 \mathrm{~g} / \mathrm{dl}$, bone involvement), as well as positive Bence Jones proteinuria. Our patient was placed under a chemotherapy regimen Cylclophosphamide-Dexamethazone-Thalidomide (CDT), associated with bisphosphonates. He presented ten days after diagnosing his myeloma a medullary compression treated surgically and whose histopathological study had found asclerogenic fibrosis without individualized plasmocytic elements in the bone and cartilaginous tissues. He has reported for 20 days the appearance of some skin lesions slightly pruriginous sitting in the genital area. Clinical examination revealed multiple papulonodular lesions which are soft, fleshless, painless, resting on healthy skin and sitting at the base of the penis (Fig. 1). The remainder of the dermatological examination was without anomaly. The cutaneous biopsy revealed deposits of an anthropic eosinophilic substance, enhanced by the violet crystal (Fig. 2a) and the Congo red (Fig. 2b) with a yellowish green dichroism in polarized light evoking nodular cutaneous amyloidosis. The systematic assessment was without abnormalities, including: Renal and hepatic function, $24 \mathrm{~h}$ proteinuria, thyroid biological examinations, chest $\mathrm{x}$-Ray, abdominal ultrasound, CT scan of brain, chest, abdomen and pelvis as well as troponin, electrocardiogram and echocardiography. The histological study of the accessory salivary gland biopsy (ASGB) did not find amyloid deposits. Medullary compression secondary to amyloidosis was mentioned in the absence of plasmocyte elements at the vertebral level. A re-reading of the vertebral

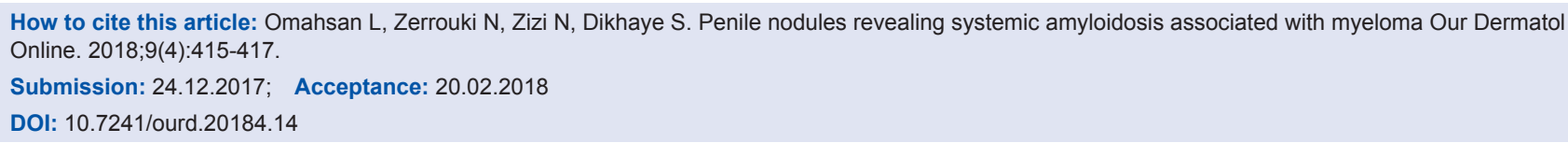




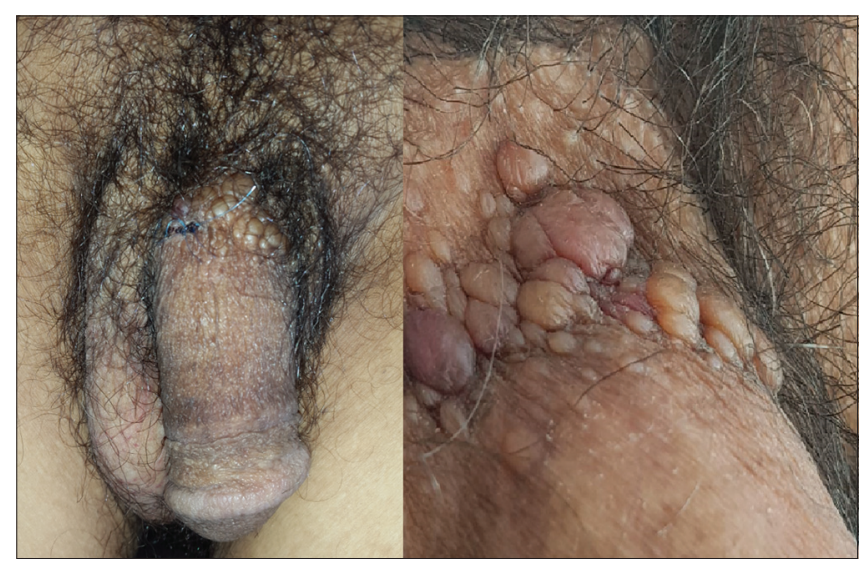

Figure 1: Multiple papulo-nodular lesions resting on healthy skin and sitting at the base of the penis.

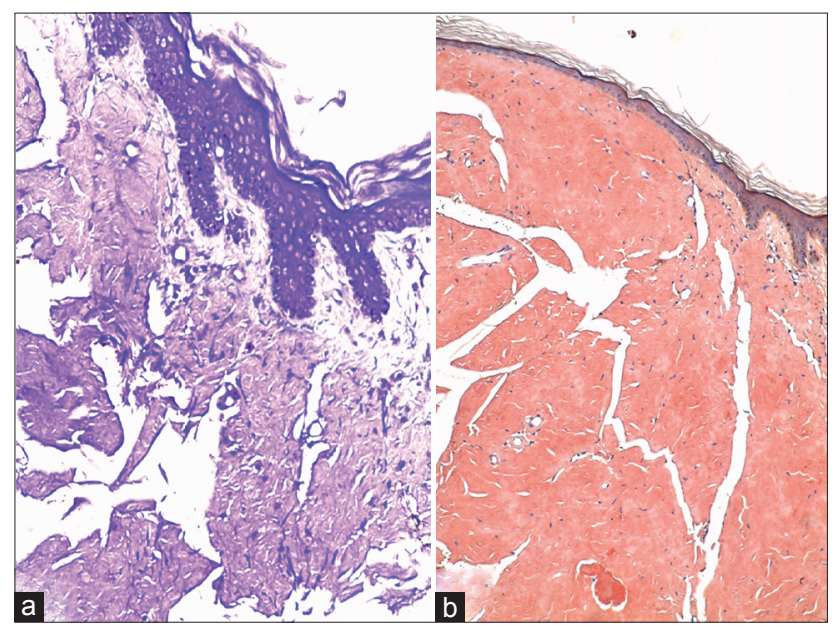

Figure 2: (a) Deposits of an anthropic eosinophilic substance, violetcrystal+ (b) Yellowish green dichroism in polarized light.

piece allowed us to retain the diagnosis of a double localization of amyloidosis associated with myeloma. Prior to the study, patient gave written consent to the examination and biopsy after having been informed about the procedure.

\section{DISCUSSION}

In addition to macular and lichenoid forms, nodular cutaneous amyloidosis is the rarest clinical form, and about a hundred cases have been described in the literature [2]. The most common clinical form is a single or rarely multiple nodule sitting at the acral level, the face, scalp or extremities [3]. Penile localization remains rare, and 14 cases have been reported in the literature with localized involvement in the glans penis [1]. In our case, the lesions of cutaneous amyloidosis were found at the level of the base of the penis without damage of the glans.
Although rare, nodular cutaneous amyloidosis is often associated with a systemic disease including Sjogren's syndrome, or a multiple myeloma dysproteinemia such as the case of our patient. The risk of evolving to systemic amyloidosis is $10 \%$ [4]. Our patient has presented a second localization at the spinal level. The mechanism underlying spontaneous vertebral compression fractures in amyloidosis has not been identified [5]. Once the diagnosis of nodular skin amyloidosis is retained, anamnesis, a complete clinical examination, as well as a serum electrophoresis and urinary proteins, ASGB, rectal or abdominal fat biopsy must be performed In order to exclude an amyloid deposit at the extracutaneous level [1].

The treatment of systemic amyloidosis associated with myeloma is not standardized; it relies mainly on chemotherapy. The treatment of the vertebral impairment is also based on chemotherapy with a total excision of lesions [5].

\section{CONCLUSION}

Our case remains original by the exceptional double localization of amyloidosis, as well by nodules well individualized at the base of the penis as well as the vertebral localization causing a medullar compression. The association of nodular skin lesions to a myeloma should evoke the diagnosis of amyloidosis and perform a skin biopsy without restricting the systematization assessment that must be guided by the patient's history and physical examination.

\section{ACKNOWLEDGEMENTS}

- We would like to thank Dr. Charif Iliass certified in medical English for his English translation.

- We would also like to thank Pr Rimani Mounia for his expertise in anatomopathology.

\section{CONSENT}

The examination of the patient was conducted according to the Declaration of Helsinki principles.

\section{REFERENCES}

1. Merika EE, Darling M, Craig P, Paul M, Francis N, Lachmann H, et al. Primary cutaneous amyloidosis of the glans penis. Two case reports and a review of the literature. Br J Dermatol. 2014;170:730-4.

2. Santos-Juanes J, Galache C, Curto JR, Astudillo A, Sánchez del Río J. Nodular primary localized cutaneous amyloidosis. 
www.odermatol.com

J Eur Acad Dermatol Venereol. 2004;18:224-6.

3. Elder DE, Elenitsas R, Johnson BL, Jr, Murphy GF, Xu X. Lever's histopathology of the skin. $10^{\text {th }}$ ed. Philadelphia: Lippincott Williams \& Wilkins; 2009. pp. 870-6.

4. Woollons A, Black MM. Nodular localized primary cutaneous amyloidosis: a long-term follow-up study. Br J Dermatol 2001;145:105-9.

5. Wu X, Feng J, Cao X, Zhang L, Zhou D, Li J. Atypical immunoglobulin light chain amyloidosis: Spontaneous vertebral compression fracture, liver involvement, and bone marrow involvement report of 3 cases and review of the literature. Medicine. 2016;95:e4603.

Copyright by Loubab Omahsan, et al. This is an open access article distributed under the terms of the Creative Commons Attribution License, which permits unrestricted use, distribution, and reproduction in any medium, provided the original author and source are credited.

Source of Support: Nil, Conflict of Interest: None declared. 